University of Nebraska - Lincoln

DigitalCommons@University of Nebraska - Lincoln

Faculty Publications: Department of

Entomology

Entomology, Department of

2009

Efficacy of Neonicotinoid Seed Treatments to Reduce Soybean Aphid Populations Under Field and Controlled Conditions in Nebraska

Leonardo C. Magalhaes

University of Nebraska-Lincoln

Thomas E. Hunt

University of Nebraska-Lincoln, thunt2@unl.edu

Blair D. Siegfried

University of Nebraska-Lincoln, bsiegfried1@ufl.edu

Follow this and additional works at: https://digitalcommons.unl.edu/entomologyfacpub

Part of the Entomology Commons

Magalhaes, Leonardo C.; Hunt, Thomas E.; and Siegfried, Blair D., "Efficacy of Neonicotinoid Seed Treatments to Reduce Soybean Aphid Populations Under Field and Controlled Conditions in Nebraska" (2009). Faculty Publications: Department of Entomology. 300.

https://digitalcommons.unl.edu/entomologyfacpub/300

This Article is brought to you for free and open access by the Entomology, Department of at DigitalCommons@University of Nebraska - Lincoln. It has been accepted for inclusion in Faculty Publications: Department of Entomology by an authorized administrator of DigitalCommons@University of Nebraska - Lincoln. 


\title{
Efficacy of Neonicotinoid Seed Treatments to Reduce Soybean Aphid Populations Under Field and Controlled Conditions in Nebraska
}

\author{
LEONARDO C. MAGALHAES,$^{1}$ THOMAS E. HUNT, ${ }^{2}$ AND BLAIR D. SIEGFRIED ${ }^{1,3}$
}

\begin{abstract}
J. Econ. Entomol. 102(1): 187-195 (2009)
ABSTRACT The soybean aphid, Aphis glycines Matsumura (Hemiptera: Aphididae), is native to Asia and was recently (2000) detected in North America. Since then, it has become a significant threat to U.S. soybean production. Although neonicotinoid insecticide seed treatments, imidacloprid and thiamethoxam, have been suggested as a method of control, the season-long efficacy is still uncertain. Therefore, the use of imidacloprid and thiamethoxam seed treatments to control soybean aphid in Nebraska were examined. Soybean aphid populations were monitored weekly in an irrigated field study planted during the later half of the typical Nebraska planting window during 2005 and 2006. Imidacloprid and thiamethoxam were quantified by leaves through time, and leaf specific bioassays were conducted. In 2005, aphid populations were very low; however, in 2006 aphid numbers were significantly higher than 2005 , reaching $\approx 1,200$ aphids per plant in the untreated plots. Aphid injury significantly reduced yield and individual seed size in 2006. Imidacloprid significantly reduced aphid densities in 2006 but not below the economic threshold. In 2006, thiamethoxam held aphid densities below the economic threshold. Leaf specific bioassays and leaf specific imidacloprid and thiamethoxam quantification indicated that thiamethoxam was present in the plant at higher concentrations and for a longer period.
\end{abstract}

KEY WORDS Glycine max, seed treatment, thiamethoxam, imidacloprid

Since its detection in North America in 2000, the soybean aphid, Aphis glycines (Matsumura) (Hemiptera: Aphididae) has spread rapidly and can be found from Ontario to northern Mississippi and Virginia to Nebraska. Soybean aphid can be found in 21 U.S. states and three Canadian provinces, affecting up to $80 \%$ of U.S. soybean, Glycine max (L.) Merr., production (Venette and Ragsdale 2004).

The soybean aphid is a heterocious holocyclic species, alternating hosts and undergoing sexual and asexual reproduction during part of its life cycle (Ragsdale et al. 2004). In much of the current soybean aphid range, the insects migrate from common buckthorn, Rhamnus cathartica (Rhamnales: Rhamnaceae), the primary overwintering host, to soybean during the spring or early summer, where they can rapidly reach high population densities under optimal conditions. In Michigan, population densities of up to 13,000 aphids per plant have been recorded (DiFonzo and Hines 2002), which is well above the economic threshold of 273 aphids per plant (Ragsdale et al. 2007). In Nebraska, however, most soybean aphid infestations are believed to be the result of the summer migrations from northern and eastern infested fields, and aphid colonies typically begin to be observed later in the

\footnotetext{
${ }^{1}$ Department of Entomology, 202 Entomology Hall, University of Nebraska, Lincoln, NE 68583.

${ }^{2}$ Haskell Agricultural Laboratory, University of Nebraska, Concord, NE 68728.

${ }^{3}$ Corresponding author, e-mail: bsiegfried1@unl.edu.
}

season (mid- to late July), with population buildup occurring primarily in late July through August (Hunt 2004). Small colonies are first observed on the undersides of the topmost soybean leaves. Soybean aphid pressure is highest in northeast Nebraska, where most economic injury is observed. As a result of differences in seasonal infestation patterns and temperatures during population buildup, soybean aphid pressure above the economic threshold is more variable in Nebraska than in states and provinces to the north and east.

Although soybean aphid has many native natural enemies in North America, in Nebraska, Orius insidiosus (Say) seems to be the most important soybean aphid natural enemy (Brosius et al. 2007). However, soybean aphid populations are not reliably suppressed by natural enemies, resulting in outbreaks and significant yield losses in soybean production (Ostlie 2001, Myers et al. 2005b). In addition to yield reduction, soybean aphid also can cause indirect effects by transmitting diseases (Clark and Perry 2002, Burrows et al. 2005), promoting sooty mold growth (Hirano et al. 1996), reducing chlorophyll content (Diaz-Montano et al. 2007) and impairing photosynthesis (Macedo et al. 2003). Therefore, there is a need to develop soybean aphid management tools and strategies that do not solely rely on native natural enemies. Different control methods that have been studied include natural enemy importation from its native habitat in Asia (Heimpel et al. 2004), 
use of resistant varieties ( $\mathrm{Li}$ et al. 2004, Mensah et al. 2005, Hesler and Dashiell 2007), and foliar insecticide application (Myers et al. 2005a).

Currently, soybean farmers rely primarily on chemical control. A single foliar application of $\lambda$-cyhalothrin or chlorpyrifos during early soybean reproductive stages (R2 to R3) has been demonstrated to significantly reduce yield loss (Myers et al. 2005a). The current extension recommendation to soybean farmers is to scout fields and only apply foliar insecticides when the economic threshold is reached (250 aphids per plant) and soybean aphid populations are increasing (Ragsdale et al. 2007), which may occur at various plant stages depending on the location. Systemic insecticides applied as seed treatments may offer increased selectivity over foliar applied insecticides (Krauter et al. 2001, Albajes et al. 2003) and provide long-term plant protection (Nault et al. 2004). In soybean, neonicotinoid seed treatments have been used to control early season bean leaf beetles (Cerotoma trifurcata Forster) that vector bean mosaic virus (BMV) (Bradshaw et al. 2003); however, they may not impact soybean aphid populations (Johnson et al. 2008). The insecticide class also is highly effective for control of various piercing-sucking insects, such as soybean aphid (Maienfisch et al. 2001a, Castle et al. 2005, Tomizawa and Casida 2005). Neonicotinoid insecticide seed treatments are increasingly being used in the north central United States, including Nebraska, for management of bean leaf beetle in soybean, and they also have been suggested as a possible control method for this new soybean pest.

Neonicotinoids are a new insecticide class that act as agonists at the postsynaptic acetylcholine receptor and are generally used as systemic insecticides (Tomizawa and Casida 2003). McCornack and Ragsdale (2006) conducted an efficacy trial for thiamethoxamtreated seeds against soybean aphid, indicating that thiamethoxam is effective during the early vegetative stages (49 d after planting), significantly reduces cumulative aphid-days, and aphid mortality was higher in older leaves; however, in only 1 of $4 \mathrm{yr}$ did the thiamethoxam seed treatment protect soybean yield. In Iowa, thiamethoxam seed treatments, targeting bean leaf beetles, did not significantly effect aphid population growth or protect yield (Johnson et al. 2008). Although neonicotinoid-treated seeds were evaluated as a control method for soybean aphid in Minnesota and indirectly in Iowa, such treatments should be evaluated for the environment and seasonal relationship between the crop and pest for a particular region. The objective of the current study was to investigate imidacloprid and thiamethoxam seed treatments for managing soybean aphid in Nebraska.

\section{Materials and Methods}

Field Site and Experimental Design. Research plots were located at the University of Nebraska Northeast Research and Extension Center Haskell Agricultural Laboratory (Concord, NE). In 2005, the soil type was an Alcester silt loam with 2-6\% slope, and in 2006 the soil was a Maskell loam with 2-6\% slope. The organic matter was $3-4 \%$ in both soils. The plots were located in soybean fields under a 2-yr corn (Zea mays L.)soybean rotation. Irrigation was applied as is common in Nebraska soybean production. Nearly $48 \%$ of Nebraska's soybean are irrigated (USDA 2007), and no significant effects have been observed in soybean aphid population dynamics between irrigated and rain-fed soybean in northeastern Nebraska (Svehla 2007). Approximately $2.54 \mathrm{~cm}$ (1 in.) of water was applied through an overhead sprinkler system on 18 July, 5 August, 24 August, and 2 September in 2005 and on 13 July, 18 July, 27 July, 2 August, and 16 August in 2006. The planting density was 430,000 seeds / ha. Plots consisted of four rows each, $0.762 \mathrm{~m}$ apart, $11 \mathrm{~m}$ long. After double disking for seed bed preparation, fields were planted on 19 May 2005 and 23 May 2006. The varieties used were Syngenta S27-T7 (2005) and Syngenta S23-Z3 (2006).

The experiment included four treatments replicated four times. Treatments included 1) an imidacloprid (Gaucho 480FS, Gustafson LLC, Dallas, TX) seed treatment at a rate of $62.5 \mathrm{~g}$ (AI) / $100 \mathrm{~kg}$ of seed; 2) a thiamethoxam (Cruiser 5FS, Syngenta Crop Protection, Greensboro, NC) seed treatment at a rate of $50 \mathrm{~g}$ (AI) / $100 \mathrm{~kg}$ of seed; 3) an untreated control; and 4) an aphid-free treatment, where soybean aphid populations were kept very low by applying the foliar insecticide $\lambda$-cyhalothrin (Warrior, Syngenta Crop Protection) at a rate of $0.028 \mathrm{~kg}(\mathrm{AI}) / \mathrm{ha}$. Warrior was applied on 19 August in 2005 and on 20 July and 12 August in 2006.

A. glycines Population Estimation and Soybean Yield. Soybean aphids were sampled weekly from before they appeared (late June) until populations collapsed (early September). In 2005, due to very low natural aphid numbers, the plots were artificially infested on 29 July and 11 August by placing aphid infested leaflets ( $\approx 5-10$ aphids/leaflet) from a nearby field on the top leaflet of a soybean plant every $30 \mathrm{~cm}$ in the two middle rows. The vegetative and reproductive stages of the soybean plants also were recorded for each sampling date. Aphids were counted by destructive whole-plant counts, where at least six plants per plot per sample date were randomly selected, removed from the ground, and checked for aphids. Plants were sampled in the two middle rows and at least $2 \mathrm{~m}$ away from the plot borders.

Plant samples, 10 neighboring plants per plot, also were taken right before harvest to measure possible differences of specific yield components and seed quality. Parameters analyzed were number of pods, number of seeds per pod, dry stem weight, individual seed weight, and protein content. Seed weight was calculated by counting the number of seeds (using an automatic seed counter) in a 350-ml cup; weighing each cup, and then converted to seeds per gram. Seed moisture was the same across the different treatments, $13 \%$.

Insecticide Metabolization in Soybean Plant. The same variety used for the 2006 season, Syngenta S23Z3, was used for this experiment. This experiment 
included four replicates of three treatments: 1) imidacloprid-treated seed; 2) thiamethoxam-treated seeds; and 3) an untreated control. Seed treatments used the same rates previously described. Three seeds were planted in 15-cm-diameter by 17 -cm-deep pots in a soil mix containing sand/soil/peat/perlite in a 2:1:3:3 ratio. After germination, the seedlings were thinned to one plant per pot to reduce competition. Plants were watered daily and fertilized weekly with a soluble fertilizer $(20 \mathrm{~N}-10 \mathrm{P}-20 \mathrm{~K})$. Plants were grown in greenhouses at $25 \pm 7^{\circ} \mathrm{C}$ under 400 -Watt highintensity discharge lamps with a photoperiod of 16:8 (L:D) h. Vegetative stages were recorded daily.

Two sets of bioassays were performed: one set on newly emerged leaves and one set on 3-wk-old leaves. For each bioassay, a leaf was randomly selected from a specific node during a specific vegetative stage from each treatment, excised, and transferred to the laboratory to perform bioassays. Only even nodes were used. Nodes 2 (V3), 4 (V5), 6 (V7), 8 (V9), and 10 (V11) were used for the newly emerged leaf experiment, and nodes 2 (V9), 4 (V12), and 6 (V13) were used for the 3-wk-old leaf experiment. Once the leaf was excised, the plant was discarded, and another leaf was taken from a new, nonexcised plant. Leaves were placed in opaque, plastic trays (C-D International, Pitman, NJ) containing eight square cells $(10 \mathrm{~cm}$ in width by $8 \mathrm{~cm}$ in depth). In each cell there was a rounded glass tube $(1 \mathrm{~cm}$ in diameter by $5 \mathrm{~cm}$ in depth) attached to the tray with adhesive tape. Five milliliters of water was dispensed into the tube, which allowed the leaf to survive for more than a week. The leaves were kept aphid-free overnight $(\approx 12 \mathrm{~h})$ to allow the recovery of leaf turgidity.

Soybean Aphid Population Growth. After leaf recovery, 25 soybean aphids were carefully transferred to the leaves using a fine camel's-hair paintbrush. To avoid aphid escapes, each cell was sealed with a porous transparent plastic lid (C-D International). After $1 \mathrm{wk}$, the number of dead and living aphids was recorded. Aphids were considered dead when unable to move with probing or when they had changed color to brown or bright red. The trays were held in a growth chamber at $25^{\circ} \mathrm{C}, 75 \pm 5 \% \mathrm{RH}$, and a photoperiod of 16:8 (L:D) h. The aphids were obtained from a soybean aphid laboratory colony initiated in July 2005 from soybean aphids collected from infested fields near the University of Nebraska Northeast Research and Extension Center Haskell Agricultural Laboratory (Concord, NE). The same procedure was repeated again three wk later with the leaves from the nodes and plant vegetative stages mentioned above to evaluate possible insecticide degradation in the plant.

Spatial and Temporal Quantification of Insecticide Levels in Leaves. Leaves from specific nodes were randomly collected from field plots throughout soybean development to quantify imidacloprid and thiamethoxam concentrations by node and soybean vegetative stage. Collected leaves were kept on ice in the field and later transferred to and stored at $-20^{\circ} \mathrm{C}$ until further analysis.
Because of the extremely low levels of insecticide in the leaves, leaves from the same nodes, same collection day were pooled to concentrate the insecticides for the following analysis. Chilled leaves were frozen in liquid nitrogen and ground with a ball grinder for two min. Ground tissue ( $10 \mathrm{~g}$ ) was transferred to $50-\mathrm{ml}$ tubes (VWR International, San Diego, CA) and $200 \mu \mathrm{l}$ $(200 \mathrm{ng} / \mathrm{ml})$ of terbutylazine (Sigma-Aldrich, Milwaukee, WI) was added as a surrogate. Acetonitrile (35 $\mathrm{ml}$ ) (Sigma-Aldrich) was then added to the leaves and left overnight $(\approx 14 \mathrm{~h})$ at $4^{\circ} \mathrm{C}$ to extract the insecticides.

After the extraction, samples were shaken for $30 \mathrm{~min}$ by using a wrist-action shaker and centrifuged for 20 min at 3,500 rpm. A 10-ml aliquot of the supernatant was mixed with $100 \mathrm{ml}$ of double-distilled water and passed through a solid phase extraction (SPE) cartridge (Waters Oasis HLB $6 \mathrm{cc}, 200 \mathrm{mg}$, product no. WAT106202) (Waters, Milford, MA) connected to a vacuum manifold. The SPE cartridge was prepared previously by sequential washing with $5 \mathrm{ml}$ of acetonitrile, $5 \mathrm{ml}$ of methanol (Sigma-Aldrich), and $5 \mathrm{ml}$ of double-distilled water. The solution load took $\approx 40-50$ min under the slight vacuum, after which the cartridge was washed with a $30 \%$ (vol:vol) methanol/water solution $(5 \mathrm{ml})$.

The insecticides were eluted from the SPE cartridge with $2 \mathrm{ml}$ of methanol into a disposable culture tube (10 by $75 \mathrm{~mm}$ ) (Thermo Fisher Scientific, Waltham, MA), and $100 \mu \mathrm{l}$ of ${ }^{13} \mathrm{C}_{3}$-labeled atrazine $(40 \mathrm{ng} / \mathrm{ml})$ (Merck, Whitehouse Station, NJ) was added as an internal standard. The eluant was then evaporated to $\approx 200-300 \mu \mathrm{l}$ at room temperature under a flow of nitrogen over a period of $2 \mathrm{~h}$. The concentrated solution was diluted to a final volume of $1.1 \mathrm{ml}$ with double-distilled water and filtered with a syringeless filter HPLC vial $(0.45-\mu \mathrm{m}$ pore size) (Whatman UNIPREP, Florham Park, NJ).

The extracts were analyzed by reverse-phase highperformance liquid chromatography (HPLC)/tandem mass spectrometry (MS/MS) by using a Waters 2695 HPLC autosampler/pump coupled to a Finnegan LCQ (Thermo Fisher Scientific) ion-trap mass spectrometer. HPLC separation was accomplished by use of a Luna C8 (5- $\mu \mathrm{m}$ particle size) column ( 250 by 2 $\mathrm{mm}$ i.d.) (Phenomenex, Torrance, CA) and distilled water (A):methanol ( $0.1 \%$ formic acid) (B) mobile phase at a flow rate of $0.3 \mathrm{ml} / \mathrm{min}$. The mobile phase gradient was initially $80 \%$ A for 2 min followed by a nonlinear change to $80 \% \mathrm{~B}$ at $8 \mathrm{~min}$. The gradient was held constant at $80 \% \mathrm{~B}$ until $20 \mathrm{~min}$ when the gradient was returned to the initial conditions and held for another $10 \mathrm{~min}$ to reequilibrate the column for a total run time of $30 \mathrm{~min}$. The LCQ mass spectrometer was operated in atmospheric pressure chemical ionization (APCI) mode at $350^{\circ} \mathrm{C}$ with the capillary voltage and temperature set at $3 \mathrm{kV}$ and $150^{\circ} \mathrm{C}$, respectively. The daughter ion transition used for the detection of imidacloprid was $m / z 256->210$ at $30 \%$ collision energy, whereas for thiamethoxam, the transition of $m / z 292$ $>211$ at $25 \%$ collision energy was used. The isolation 

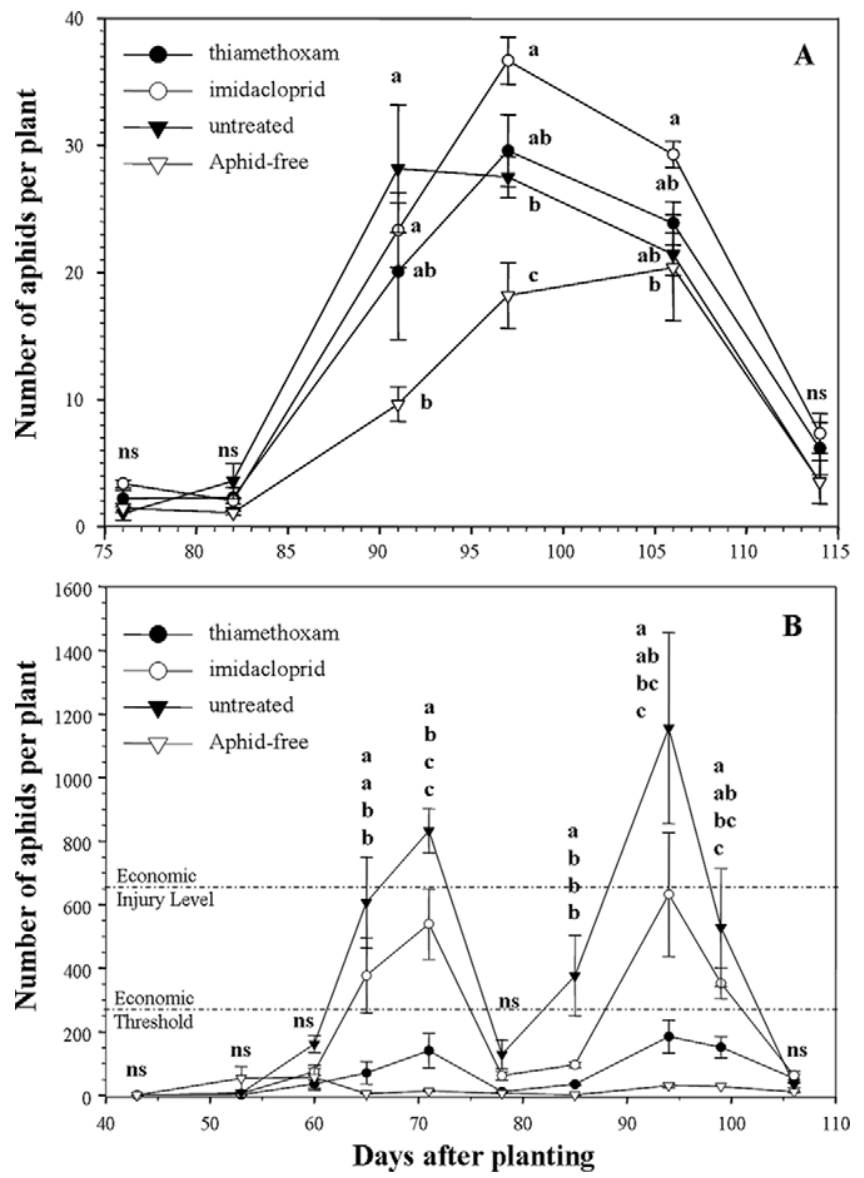

Fig. 1. Mean \pm SEM number of soybean aphid per plant in 2005 (A) and 2006 (B) were calculated by averaging four replicates. Treatments included imidacloprid (Gaucho 480FS, Gustafson LLC) seed treatment at a rate of $62.5 \mathrm{~g}$ (AI) / 100 $\mathrm{kg}$ seed; thiamethoxam (Cruiser 5FS, Syngenta Crop Protection) seed treatment at a rate of $50 \mathrm{~g}$ (AI)/100 kg seed; an untreated control; and an aphid-free treatment, foliar insecticide application $\lambda$-cyhalothrin (Warrior, Syngenta Crop Protection) at a rate of $0.028 \mathrm{~kg}(\mathrm{AI}) / \mathrm{ha}$. Means with the same letter on a given date are not significantly different $(P<0.05$, Fisher protected LSD). EIL and economic threshold, 674 and 273 aphids per plant, respectively (Ragsdale et al. 2007).

width was 3 amu, and the activation time was $30 \mathrm{~ms}$ for both analytes.

Statistical Analysis. The aphid counts in the field experiment were analyzed as a repeated measure randomized complete block design (RCBD) using analysis of variance (ANOVA). The covariance model used for the repeated measure analysis was the firstorder antedependence model because the lowest Akaike's Information Criteria was achieved using this structure. Once the treatment date interaction was significant $(P<0.05)$ by ANOVA, then Fisher protected least significant difference (LSD) was performed to identify differences among treatment means by date $(P<0.05)$ (PROC MIXED) (SAS Institute 2002). The soybean yield, number of seeds per gram, and plant samples parameters were analyzed as RCBD using one-way ANOVA. The aphid count in the insecticide metabolization experiment was analyzed as a complete randomized design. For all the analyses, the mixed model was used (PROC MIXED) (SAS Institute 2002).

\section{Results}

A. glycines Population Densities. Although plots were artificially infested with soybean aphids twice in 2005 , the number of aphids per plant in every treatment was very low (Fig. 1A). At $91 \mathrm{~d}$ after planting, there was a significant difference in mean number of aphids per plant between treatments $(F=5.03$; $\mathrm{df}=$ $3,9 ; P=0.0257)$. Aphids were more abundant in the imidacloprid treatment in 2005, $97 \mathrm{~d}$ after planting, reaching a peak of 46.5 aphids per plant. Aphid numbers throughout the season for every treatment were well below an average economic threshold (273 aphids per plant) (Ragsdale et al. 2007).

In 2006, aphid numbers were much higher than 2005 and two distinct peaks were observed at 71 and $94 \mathrm{~d}$ after planting (Fig. 1B). The presence of two peaks could be related to very warm temperatures, higher than $32^{\circ} \mathrm{C}$, between 74 and $84 \mathrm{~d}$ after planting, which drastically reduces nymph survival (Hirano et al. 1996). The heat, combined with the presence of abun- 
Table 1. Comparison of soybean yields in 2005 and 2006 and number of soybean seeds per gram (mean \pm SEM; $n=4)$ among the treatments tested

\begin{tabular}{lccc}
\hline \multicolumn{1}{c}{ Treatment } & $\begin{array}{c}\text { Yield (2005) } \\
(\mathrm{kg} / \mathrm{ha})\end{array}$ & $\begin{array}{c}\text { Yield }(2006) \\
(\mathrm{kg} / \mathrm{ha})^{a}\end{array}$ & $\begin{array}{c}\text { Seeds/g } \\
(2006)^{a}\end{array}$ \\
\hline Aphid-free & $4,251.11 \pm 37.180 \mathrm{a}$ & $4,380.79 \pm 96.75 \mathrm{a}$ & $6.45 \pm 0.14 \mathrm{a}$ \\
Thiamethoxam & $4,101.98 \pm 144.53 \mathrm{a}$ & $4,165.78 \pm 86.00 \mathrm{a}$ & $6.74 \pm 0.03 \mathrm{~b}$ \\
Imidacloprid & $4,163.38 \pm 38.53 \mathrm{a}$ & $4,199.38 \pm 71.89 \mathrm{a}$ & $6.89 \pm 0.11 \mathrm{~b}$ \\
Untreated & $4,243.38 \pm 36.06 \mathrm{a}$ & $3,641.70 \pm 137.74 \mathrm{~b}$ & $7.19 \pm 0.06 \mathrm{c}$ \\
\hline
\end{tabular}

Soybean seeds per gram was based on sampling 10 neighboring plants. From these plants, a seed sample was taken and placed in a $350-\mathrm{ml}$ cup and automatically counted.

a Means in the columns followed by a different letter are significantly different $(P<0.05$; Fisher's protected LSD).

dant natural enemies in 2006, mainly Orius sp. (Brosius et al. 2007), may have been the cause of the population decline. This decline in aphid density was noted in other areas of the research farm (Svehla 2007). In untreated plots, the mean number of aphids per plant was well above an average economic threshold and economic injury level (EIL) (674 aphids per plant) (Ragsdale et al. 2007), reaching almost 1,200 aphids per plant $94 \mathrm{~d}$ after planting. Imidacloprid significantly reduced aphid densities but not below the economic threshold. However, the mean aphid number per plant (632) was not above the EIL. In contrast, aphid densities remained below the economic threshold $100 \mathrm{~d}$ after planting in the thiamethoxam treatment. Two applications of $\lambda$-cyhalothrin (aphid-free treatment) kept treated plots almost free of soybean aphids.

Soybean Yield. There was no significant difference in yield among the treatments in 2005 ( $F=1.08$; $\mathrm{df}=$ 3,$9 ; P=0.405$ ) (Table 1 ). However, aphid injury significantly reduced yield in 2006 . Yield was significantly lower for the untreated control than yields for other treatments $(F=12.44$; $\mathrm{df}=3,9 ; P=0.0015)$ (Table 1$)$. There was a significant $(17 \%)$ yield reduction in the control treatment compared with aphidfree treatment $(P=0.0003, \mathrm{LSD})$. There were no significant differences in yield between the aphid-free treatment and the seed treatments. The aphid injury seemed to have affected yield by reducing individual seed weight $(F=14.06$; $\mathrm{df}=3,9 ; P=0.0010)$ (Table $1)$. There were significantly fewer seeds per gram for the aphid-free treatment than for the untreated control or seed treatments. There were significantly fewer seeds per gram for the seed treatments than for the untreated control. There was no significant difference between the number of seeds per gram between the seed treatments. There were no significant differences in the number of pods, number of seeds per pod, dry stem weight, and protein concentration between treatments (data not shown).

Insecticide Degradation in Soybean Plant. Imidacloprid and thiamethoxam significantly reduced aphid numbers on newly emerged leaves from leaf node 2-10 compared with control (Fig. 2A). Aphid numbers in untreated, newly emerged leaves reached $>100$ aphids per leaf in every node tested. Imidacloprid and thiamethoxam kept aphid numbers below 40 aphids per leaf. However, in 3-wk-old leaves, only thiame- thoxam significantly reduced aphid densities (Fig. 2B).

Spatial and Temporal Quantification of Insecticide Levels in Leaves. Thiamethoxam was detected in soybean leaves longer and at higher concentrations than imidacloprid (Table 2). At node 1, $17 \mathrm{~d}$ after planting, thiamethoxam was found in leaves at a concentration of $105 \mathrm{ng} / \mathrm{g}$ leaf, approximately four-fold higher than imidacloprid ( $25.3 \mathrm{ng} / \mathrm{g}$ leaf). In general, the concentrations of both insecticides decreased as the leaf aged. The exception was imidacloprid at node 1 , where the concentration increased from 25.3 to $33.3 \mathrm{ng} / \mathrm{g}$ leaf after $10 \mathrm{~d}$ ( $27 \mathrm{~d}$ after planting) and then quickly dropped after $13 \mathrm{~d}$ ( $40 \mathrm{~d}$ after planting).

At node 2, the concentration of insecticide found on the leaves was 39 and $29.5 \mathrm{ng} / \mathrm{g}$ of leaf at $27 \mathrm{~d}$ after planting, thiamethoxam and imidacloprid, respectively. At node 4, thiamethoxam was detected at 3.5 $\mathrm{ng} / \mathrm{g}$ of leaf, and imidacloprid was below the limit of detection at $40 \mathrm{~d}$ after planting.

\section{Discussion}

In this study, both imidacloprid and thiamethoxam seed treatments prevented yield losses. However, only thiamethoxam provided longer control and maintained soybean aphid densities below the average economic threshold (ET) of 273 aphids per plant (Ragsdale et al. 2007) throughout the growing season (Fig. 1B). Indeed, using the recommended ET, the imidacloprid treatment would have required that a second soybean aphid control tactic be initiated. It should be noted that imidacloprid did maintain aphid numbers below the average EIL of 674 aphids per plant (Ragsdale et al. 2007). Thus, no yield reduction was observed in 2006 (the higher aphid year in our study) for thiamethoxam and imidacloprid compared with aphid-free treatment (Table 1). Insecticidal seed treatments may delay or reduce the rate of soybean aphid population growth, which may allow more time for natural enemies to take action (Satoh et al. 1995) before the EIL is reached. Because of the reduced aphid population growth rate caused by an insecticidal seed treatment, aphid density may reach the ET but not the EIL. Further research to evaluate economic thresholds for soybean treated with insecticidal seed treatments and the contribution of natural enemies in controlling soybean aphids in insecticide seed treatments may be warranted.

Although soybean yields were not significantly different between the imidacloprid and thiamethoxam seed treatments and the aphid-free control, both seed treatments resulted in lighter seeds than the aphidfree treatment. Soybean aphid impairs photosynthesis even at very low numbers (20 aphids per leaflet) (Macedo et al. 2003), which may reduce the translocation of nutrients necessary for pod and seed formation. As a result, soybean aphid may cause subtle impacts that are not always measured by yield differences.

Comparable control results have been shown in snap bean for potato leafhopper, Empoasca fabae 


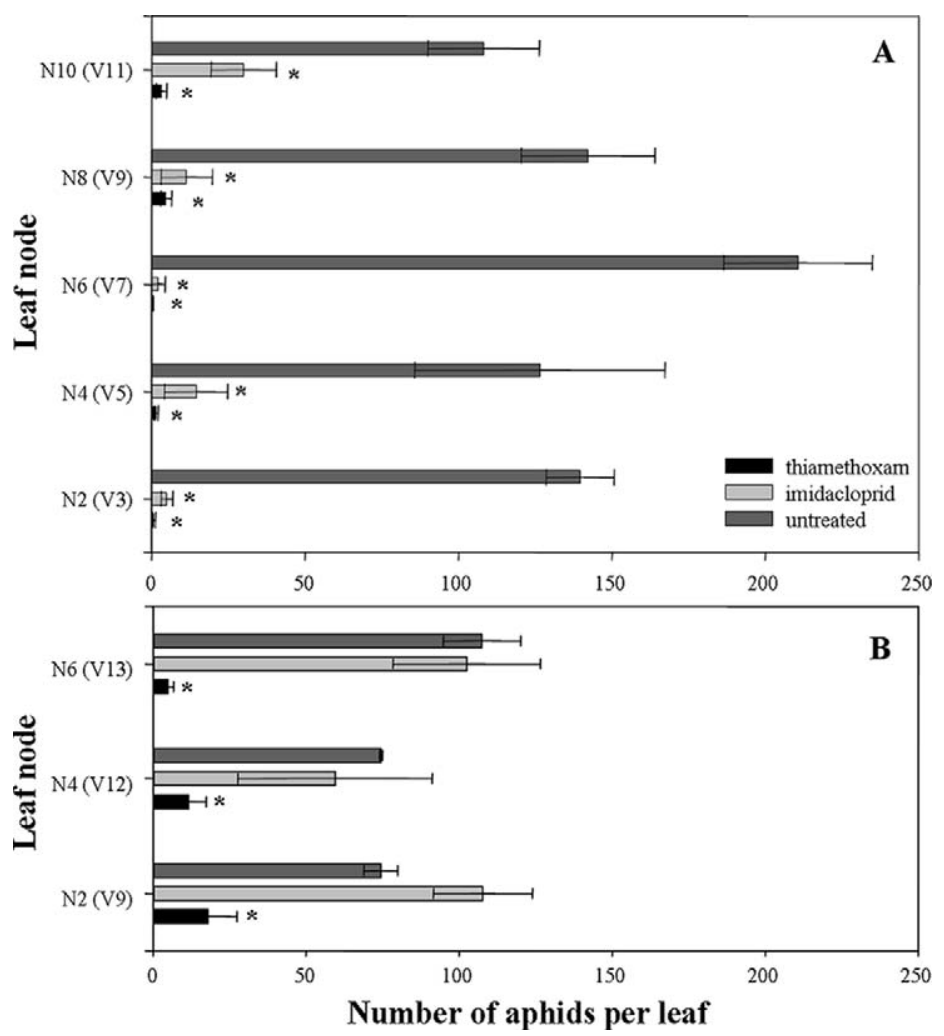

Fig. 2. Number of aphids per leaf (mean \pm SEM; $n=4)$ in newly emerged leaves (A) and 3-wk-old leaves (B). Leaves were removed from the plants and transferred to five ml tubes in trays, which 25 aphids were placed on top. Aphids were evaluated $1 \mathrm{wk}$ later. Treatments included imidacloprid (Gaucho 480FS, Gustafson LLC) seed treatment at a rate of $62.5 \mathrm{~g}$ (AI) / $100 \mathrm{~kg}$ seed; thiamethoxam (Cruiser 5FS, Syngenta Crop Protection) seed treatment at a rate of $50 \mathrm{~g}(\mathrm{AI}) / 100 \mathrm{~kg}$ seed; and an untreated control. Seeds were planted in pots with a soil mix and kept in a greenhouse. Bars with an asterisk (*) differ significantly with the untreated control $(P \leq 0.05$, Fisher protected LSD). Soybean vegetative stage is indicated in parentheses.

(Harris), infestation by Nault et al. (2004) who observed that lower rates of thiamethoxam provided more consistent and longer control than imidacloprid throughout the entire study. This control was observed despite the near absence of these insecticides in plant tissues 3-4 wk after planting. Longer thiamethoxam residual effects relative to imidacloprid have also been observed under laboratory conditions against a number of different insect orders (Maienfisch et al. 2001a). Similar results were documented with the same insecticides applied through the irrigation system for citrus trees, where thiamethoxam controlled glassy-winged sharpshooter, Homalodisca vitripennis (Germar), nymphs better than imidacloprid (Castle et al. 2005).

Thiamethoxam is a second generation neonicotinoid with water solubility of $4.1 \mathrm{~g} /$ liter (Maienfisch et al. 2001b). Although imidacloprid is less water soluble $(0.51 \mathrm{~g} /$ liter $)$ than thiamethoxam, water solubility may not be the only reason for the higher soybean aphid densities observed under field conditions. $\mathrm{LC}_{50}$ and $\mathrm{EC}_{50}$ values for soybean aphids placed on excised soybean leaves immersed in thiamethoxam and imidacloprid solutions were not significantly different

Table 2. Concentration of imidacloprid and thiamethoxam in different soybean leaf nodes

\begin{tabular}{|c|c|c|c|c|c|c|c|c|c|c|}
\hline \multirow{3}{*}{ Insecticide } & \multicolumn{10}{|c|}{ Node } \\
\hline & \multicolumn{4}{|c|}{$\mathrm{N} 1$} & \multicolumn{3}{|c|}{$\mathrm{N} 2$} & \multicolumn{3}{|c|}{$\mathrm{N} 4$} \\
\hline & 17 dap $^{a}$ & 27 dap & 40 dap & 49 dap & 27 dap & 40 dap & 49 dap & 40 dap & 49 dap & 56 dap \\
\hline Imidacloprid & 25.3 & 33.3 & 2.7 & $-b$ & 29.5 & 3.8 & - & - & - & - \\
\hline Thiamethoxam & 105 & 88.1 & 9.6 & 3.8 & 39 & 5.1 & 1.2 & 3.5 & 1.4 & 1.7 \\
\hline
\end{tabular}

Concentrations were determined by performing a reverse-phase HPLC/MS/MS. Each mean represents a pool concentration of at least 12 leaves from specific nodes.

${ }^{a}$ dap, days after planting.

${ }^{b}$ Below limit of detection. 
(Magalhaes et al. 2008). In the current study, water was not limiting because plots were irrigated, so there are likely factors other than translocation differences contributing to the differences observed in yield and the number of aphids per plant between the treatments.

Results from the insecticide degradation study indicated imidacloprid may be metabolized faster in the plant, which may have contributed to the differences observed in field performance. Insecticide movement in the plant is mainly via xylem toward leaves (Maienfisch et al. 2001b, Weichel and Nauen 2003). Thus, as long as there is enough insecticide to be taken up by the plants, new leaves should be protected from pest herbivores. In the insecticide degradation study, new leaves from imidacloprid and thiamethoxam treated plants had significantly fewer aphids throughout the entire duration of the study (through soybean stage V11) (Fig. 2A). In contrast, only the 3-wk-old leaves from thiamethoxam-treated plants had significantly reduced aphid numbers (Fig. 2B), which suggests faster imidacloprid metabolism in the plant.

The higher levels of aphid control by thiamethoxam than imidacloprid that were observed in the field and insecticide degradation studies were reflected in the higher concentrations of thiamethoxam measured in the leaves (Table 2). As the plant grows, less insecticide is available in the soil. Because these insecticides are mainly translocated via xylem, once they are taken up by a leaf, they are not translocated in the plant to new leaves. As a result, imidacloprid and thiamethoxam were present at higher concentrations in older leaves and decreased in newer leaves as they were produced. However, thiamethoxam was detected at higher levels and for a longer time, which supports the hypothesis that imidacloprid may be metabolized faster in the plant. Neonicotinoid metabolites can be as toxic or more toxic than the parent compound (Nauen et al. 1998, Nauen and Elbert 2003); however, a wide MS/MS range scan did not identify additional significant peaks different from untreated leaves, and specific known metabolites were not detected. Thus, the metabolites probably were present at concentrations below our limit of detection and did not significantly impact soybean aphid populations in the field.

The soil mix used in the greenhouse study did not represent the biological and mineral composition found in the field experiment. The soil used was sterile and very light, sandy, and porous. Under field conditions, where microorganisms and insecticidesoil interactions are present, both insecticides would likely be degraded faster, and the reduction in aphid mortality would be observed earlier in the field than in the greenhouse study (stage V11), as has been reported previously (McCornack and Ragsdale 2006).

Another hypothesis for the efficacy differences observed could be an insecticide-soil interaction. It is common for herbicide efficacy to vary with different soil physical and biological characteristics (Pedersen et al. 1995, Cupples et al. 2000). Imidacloprid may be absorbed more tightly to soil particles and/or degraded faster by microorganisms than thiamethoxam. Such differences would reduce insecticide availability in the soil.

Although seed treatments may be efficient in reducing soybean aphid populations and preventing yield loss under certain conditions, their use should be carefully considered. The soybean aphid control reported here has not been consistent with other studies. Neither McCornack and Ragsdale (2006) in Minnesota or Johnson et al. (2008) in Iowa observed satisfactory aphid control or yield protection by using neonicotinoid seed treatments. It is important to note that although the number of aphids per plant in the untreated plots in this study was well above EIL, this infestation could be considered moderate, as $>3,000$ aphids per plant have been recorded in Nebraska and elsewhere (DiFonzo and Hines 2002). Under higher aphid pressures, seed treatments may be overwhelmed and further control tactics would be necessary. Moreover, the soybean in our study was planted during the later half of the typical Nebraska soybean planting window. Earlier planted soybean would have even lower insecticide titer, which would likely have resulted in increased aphid pressure in treated plots. Furthermore, the soybean plots in Minnesota and Iowa were not irrigated. Irrigation or adequate rain may enhance insecticide uptake by soybean plants, increasing protection against pests. Seed treatments performance under dry or drought conditions should be further evaluated.

Thus far, soybean aphid outbreaks have been unpredictable in any given field, which reduces a farmer's ability to make a confident decision in using this preventive treatment. In Nebraska, soybean aphid occurrence is even more unpredictable and generally occurs at lower densities than observed in more northern and eastern soybean production areas. Furthermore, a single foliar insecticide application has been shown to adequately prevent significant yield loss (Myers et al. 2005a). Therefore, NE soybean farmers would likely receive more consistent economic return by scouting fields and applying foliar insecticides only when necessary as indicated by economic thresholds.

\section{Acknowledgments}

We thank Jerry Echtenkamp and summer helpers for assistance during the field study. We also thank Daniel Snow and Dave Cassida for immense help in developing the HPLC/MS methodology.

\section{References Cited}

Albajes, R., C. Lopez, and X. Pons. 2003. Predatory fauna in cornfields and response to imidacloprid seed treatment. J. Econ. Entomol. 96: 1805-1813. 
Bradshaw, J. D., M. E. Rice, and J. H. Hill. 2003. Efficacy of a pyrethroid and systemic neonicotinoid to manage an insect and pathogen complex, pp. 53-60. The BCPC International Congress: Crop Science and Technology, vol. 1 and 2.

Brosius, T. R., L. G. Higley, and T. E. Hunt. 2007. Population dynamics of soybean aphid and biotic mortality at the edge of its range. J. Econ. Entomol. 100: 1268-1275.

Burrows, MEL., C. M. Boerboom, J. M. Gaska, and C. R. Grau. 2005. The relationship between Aphis glycines and Soybean mosaic virus incidence in different pest management systems. Plant Dis. 89: 926-934.

Castle, S. J., F. J. Byrne, J. L. Bi, and N. C. Toscano. 2005. Spatial and temporal distribution of imidacloprid and thiamethoxam in citrus and impact on Homalodisca coagulata populations. Pest Manag. Sci. 61: 75-84.

Clark, A. J., and K. L. Perry. 2002. Transmissibility of field isolates of soybean viruses by Aphis glycines. Plant Dis. 86: 1219-1222.

Cupples, A. M., G. K. Sims, R. P. Hultgren, and S. E. Hart. 2000. Effect of soil conditions on the degradation of cloransulam-methyl. J. Environ. Qual. 29: 786-794.

Diaz-Montano, J., J. C. Reese, W. T. Schapaugh, and L. R. Campbell. 2007. Chlorophyll loss caused by soybean aphid (Hemiptera: Aphididae) feeding on soybean. J. Econ. Entomol. 100: 1657-1662.

DiFonzo, C., and R. Hines. 2002. Soybean aphid in Michigan: update from the 2001 season: MSU Extension Bulletin E-2748. Michigan State University, East Lansing, MI.

Heimpel, G. E., D. W. Ragsdale, R. Venette, K. R. Hopper, R. J. O'Neil, C. E. Rutledge, and Z. S. Wu. 2004. Prospects for importation biological control of the soybean aphid: anticipating potential costs and benefits. Ann. Entomol. Soc. Am. 97: 249-258.

Hesler, L. S., and K. E. Dashiell. 2007. Resistance to Aphis glycines (Hemiptera: Aphididae) in various soybean lines under controlled laboratory conditions. J. Econ. Entomol. 100: 1464-1469.

Hirano, K., K. Honda, and S. Miyai. 1996. Effects of temperature on development, longevity and reproduction of the soybean aphid, Aphis glycines (Homoptera: Aphididae). Appl. Entomol. Zool. 31: 178-180.

Hunt, T. E. 2004. Soybean aphid management in Nebraska. NF 599. Univ. of Nebraska-Lincoln Extension, Institute of Agriculture and Natural Resources. Lincoln, NE.

Johnson, K. D., M. E. O’Neal, J. D. Bradshaw, and M. E. Rice. 2008. Is preventive, concurrent management of the soybean aphid (Hemiptera: Aphididae) and bean leaf betle (Coleoptera: Chrysomelidae) possible? J. Econ. Entomol. 101: 801-809.

Krauter, P. C., C. G. Sansone, and K. M. Heinz. 2001. Assessment of Gaucho (R) seed treatment effects on beneficial insect abundance in sorghum. Southwest. Entomol. 26: 143-146.

Li, Y., C. B. Hill, and G. L. Hartman. 2004. Effect of three resistant soybean genotypes on the fecundity, mortality, and maturation of soybean aphid (Homoptera: Aphididae). J. Econ. Entomol. 97: 1106-1111.

Macedo, T. B., C. S. Bastos, L. G. Higley, K. R. Ostlie, and S. Madhavan. 2003. Photosynthetic responses of soybean to soybean aphid (Homoptera: Aphididae) injury. J. Econ. Entomol. 96: 188-193.

Maienfisch, P., H. Huerlimann, A. Rindlisbacher, L. Gsell, H. Dettwiler, J. Haettenschwiler, E. Sieger, and M. Walti. 2001a. The discovery of thiamethoxam: a second-generation neonicotinoid. Pest Manag. Sci. 57: $165-176$.
Maienfisch, P., M. Angst, F. Brandl, W. Fischer, D. Hofer, H. Kayser, W. Kobel, A. Rindlisbacher, R. Senn, A. Steinemann, and H. Widmer. 2001b. Chemistry and biology of thiamethoxam: a second generation neonicotinoid. Pest Manag. Sci 57: 906-913.

Magalhaes, L. C., T. E. Hunt, and B. D. Siegfried. 2008. Development of methods to evaluate susceptibility of soybean aphid to imidacloprid and thiamethoxam at lethal and sublethal concentrations. Entomol. Exp. Appl. 128: $330-336$.

McCornack, B. P., and D. W. Ragsdale. 2006. Efficacy of thiamethoxam to suppress soybean aphid populations in Minnesota soybean. Online. Crop Management. (doi: 10.1094/CM-2006-0915-01-RS).

Mensah, C., C. DiFonzo, R. L. Nelson, and D. C. Wang. 2005. Resistance to soybean aphid in early maturing soybean germplasm. Crop Sci. 45: 2228-2233.

Myers, S. W., D. B. Hogg, and J. L. Wedberg. 2005a. Determining the optimal timing of foliar insecticide applications for control of soybean aphid (Hemiptera: Aphididae) on soybean. J. Econ. Entomol. 98: 2006 2012.

Myers, S. W., C. Gratton, R. P. Wolkowski, D. B. Hogg, and J. L. Wedberg. 2005b. Effect of soil potassium availability on soybean aphid (Hemiptera: Aphididae) population dynamics and soybean yield. J. Econ. Entomol. 98: 113120.

Nauen, R., K. Tietjen, K. Wagner, and A. Elbert. 1998. Efficacy of plant metabolites of imidacloprid against Myzus persicae and Aphis gossypii (Homoptera: Aphididae). Pestic. Sci. 52: 53-57.

Nauen, R., and A. Elbert. 2003. European monitoring, of resistance to insecticides in Myzus persicae and Aphis gossypii (Hemiptera: Aphididae) with special reference to imidacloprid. Bull. Entomol. Res. 93: 47-54.

Nault, B. A., A. G. Taylor, M. Urwiler, T. Rabaey, and W. D. Hutchison. 2004. Neonicotinoid seed treatments for managing potato leafhopper infestations in snap bean. Crop Prot. 23: 147-154.

Ostlie, K. 2001. Soybean aphid reduces yields: harvest results from insecticide strip trials. University of Minnesota, St Paul, MN. (http://www.soybeans.umn.edu/ crop/insects/aphid/studyresults.htm).

Pedersen, H. J., P. Kudsk, and A. Helweg. 1995. Adsorption and $\operatorname{Ed}(50)$ Values of 5 Soil-Applied Herbicides. Pestic. Sci. 44: 131-136.

Ragsdale, D. W., D. J. Voegtlin, and R. J. O’Neil. 2004. Soybean aphid biology in North America. Ann. Entomol. Soc. Am. 97: 204-208.

Ragsdale, D. W., B. P. McCornack, R. C. Venette, B. D. Potter, I. V. Macrae, E. W. Hodgson, M. E. O’Neal, K. D. Johnson, R. J. O'Neil, C. D. DiFonzo, et al. 2007. Economic threshold for soybean aphid (Homoptera: Aphididae). J. Econ. Entomol. 100: 1258-1267.

SAS Institute. 2002. User's manual, version 8.1. SAS Institute, Cary, NC.

Satoh, G. T., F. W. Plapp, and J. E. Slosser. 1995. Potential of juvenoid insect growth-regulators for managing cotton aphids (Homoptera: Aphididae). J. Econ. Entomol. 88: 254-258.

Svehla, S.E. 2007. The impact of irrigation and planting date on soybean aphid (Aphis glycines) population dynamics and soybean yield. M.S. thesis, University of Nebraska, Lincoln, NE.

Tomizawa, M., and J. E. Casida. 2003. Selective toxicity of neonicotinoids attributable to specificity of insect and 
mammalian nicotinic receptors. Annu. Rev. Entomol. 48: $339-364$.

Tomizawa, M., and J. E. Casida. 2005. Neonicotinoid insecticide toxicology: mechanisms of selective action. Annu. Rev. Pharmacol. Toxicol. 45: 247-268.

[USDA] U.S. Dep. Agric. 2007. A Look at Nebraska Agriculture. Agriculture in the Classroom. United States Department of Agriculture. (http://www.agclassroom.org/ kids/stats/nebraska.pdf).
Venette, R. C., and D. W. Ragsdale. 2004. Assessing the invasion by soybean aphid (Homoptera: Aphididae): where will it end? Ann. Entomol. Soc. Am. 97: 219226.

Weichel, L., and R. Nauen. 2003. Uptake, translocation and bioavailability of imidacloprid in several hop varieties. Pest Manag. Sci. 60: 440-446.

Received 26 April 2008; accepted 10 October 2008 